Journal of Economics and Behavioral Studies

Vol. 4, No. 11, pp. 635-648, Nov 2012 (ISSN: 2220-6140)

\title{
The Mortgage Foreclosure Rage: A Behavioral Perspective
}

\author{
${ }^{*}$ Beryl Y. Chang1, John R. Nofsinger2 , Caroline E. W. Glackin³ \\ ${ }^{1}$ New York University Graduate School of Arts and Science, United States \\ ${ }^{2}$ Washington State University, Pullman, United States \\ ${ }^{3}$ FACS, Shepherd University, Shepherdstown, United States \\ *beryl.chang@nyu.edu
}

\begin{abstract}
Residential real estate foreclosures reached historic records since the 2008 recession in the United States. While other studies on mortgage defaults and foreclosures focus primarily on individual causal factors leading to the outcome, this paper explores the nature and origins underlying these factors from a behavioral perspective. We argue that: (i) failures in mortgage risk management were due to overconfidence, anchoring, and reference-dependence given constraints in quantitative measurements in inter-temporal terms in a reductionist system; (ii) mortgage derivatives with outsized volume made the lending system dependent on a wider range of externalities with significant ramifications, and thereby more fragile given its misleading assumptions of uncorrelated rather than correlated market behavior; (iii) residential mortgage-backedsecurities (MBS) created illusions of control among market participants due to mental framing, myopia, and other limitations of human cognition; (iv) psychological biases were influenced by product design and lending procedures that promote short-term profits unsuited for a home mortgage; (v) product complexity reduces transparency, intensifies ambiguity aversion, self-serving biases, and default contagion that ultimately led to market breakdown and massive foreclosures. This study contributes to the theories in finance and economics through applications of behavioral measures to current market dynamics. It aims to reveal an idealized but biased system given human characteristics leading to failures in the financial and related industries and to inform policymakers on involuntary consequences in the development of home mortgage products that demand more profound reflections in the regulatory reform process.
\end{abstract}

Keywords: Mortgage foreclosure, behavioral finance, human biases, correlation, complexity

\section{Introduction}

The home foreclosure rate in the United States reached 4.58 percent in the fourth quarter of 2009 with subprime mortgage delinquency at 25.3 percent and subprime mortgages in foreclosure at 15.6 percent (Mortgage Bankers Association, 2010). The mortgage delinquency rate at the height of the financial crisis reached 11 percent in the first quarter of 2010 (Fig. 1). Before the current crisis, research findings on major factors contributing to home foreclosures had been relatively consistent. These include low FICO/credit scores, high unemployment (Edmiston and Zalneraitis, 2007), loan to value (LTV) ratios, changes in interest rates, real estate market price declines, and the overall macroeconomic conditions (Ben-Shahar, 2008). Data represent residential mortgages booked in the U.S. domestic offices of all commercial banks (Seasonally Adjusted). Borrower is in the delinquent state when misses three or more consecutive mortgage payments (90 days). Delinquency rate is an important measure predicting mortgage foreclosures. Lenders are entitled to take steps toward property foreclosure after four consecutive months of delinquency. These findings reach across multiple causes. Credit scores, such as FICO, are strong predictors of delinquency and default. While Loan-to-Value (LTV) at origination is positively correlated with delinquency (Danis and Pennington-Cross, 2008), interest rate is deemed to be a key factor in determining the relation between LTV and default risk in the borrower (Ben-Shahar, 2008). Other causes of foreclosure include 'non-recourse' loans, those with lender recovery limited to pledged collateral, along with a steep decline of home values that enable borrowers to walk away from mortgage obligations due to negative equity (Edmiston and Zalneraitis, 2007). Study results on the triggers of mortgage default include negative equity or high combined LTV (CLTV), when loan amount exceeds the property value, and illiquidity, which is indicated by high revolving unsecured credit. Other causes are unemployment shock and having a second mortgage (Elul et al., 2010). 
Fig. 1: Delinquency Rate on Single-Family Residential Mortgages

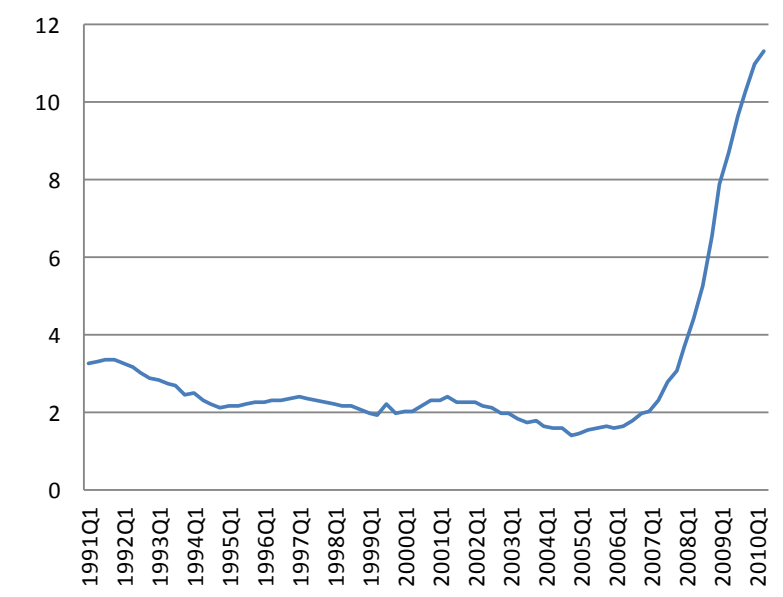

Data source: The Federal Reserve Board.

In this paper, we suggest that there were limitations in projecting performances of mortgage payments over time from an ex ante perspective. Quantitative measures used in the loan approval process are not only restrictive because they are primarily based on historical behaviors and financial performance of prospective borrowers, which may vary under different economic cycles, but also fail to capture the dynamics of the macroeconomic effects which have an indirect but significant impact on loan performance. These limitations have been noticeably exacerbated in the subprime lending market, a population most susceptible to both micro and macroeconomic transformations (Elul et al, 2010). In addition, numerous conflicts of interest existed among market participants, the investors, the borrowers, and financial intermediaries, in pursuing their respective goals in a resource-constrained economy. Moreover, these conflicts are intensified by financial innovations such as the residential mortgage-backed-securities (MBS) in an imperfect market with information asymmetry, issues of transparency, and adverse incentives. We argue that these frictions and tensions among market players grew more severe over time with competing interests therefore increase the probability of foreclosures. Specifically, while financial intermediaries take short-term profits at early stages of mortgage contracts, borrowers are expected to make mortgage payments over an extended number of years under various economic conditions. While borrowers have commonly had 15- to 30-year mortgages during the past half-century, never before have they been so highly leveraged (LTV exceeding 80\%) while experiencing a declining macroeconomic environment leading to the 2008 crisis. Further, the mortgage lending system evolved from one dominated by savings and loans institutions, which originated, underwrote, funded, and serviced the mortgages, to a system with far fewer connections between borrowers and lenders, a key component to the success of lending practice. While major causes of home foreclosures noted by other researchers were present in the mortgage meltdown, we explore the origins and effects that are specific to the massive number of home foreclosures during the 2008 crisis using a systemic and behavioral approach. In other words, while prior studies offer cautions about high default probabilities and risks of lending to certain borrowers, e.g., the subprime market, we search for drivers and causes beyond targeting the subprime market that led to the current state of the market. Considering the cognitive limitations on the borrowers' (Heidhues and Kőszegi, 2010) and the investors' part in understanding the mechanisms of the mortgage instruments, we further demonstrate how lenders develop financial products using unviable market assumptions.

As we describe the behavioral key drivers in the mortgage foreclosure malaise, our research questions are: (1) what are the human limitations from the behavioral finance point of view that contributed to the foreclosures?, (2) What were the market progressions that were at odds with product design assumptions in mortgage lending in the past decades?, (3) Why did financial innovations such as the residential MBS make the mortgage lending industry more fragile?, (4) What were the mechanisms and successions of behavioral characteristics that contributed to the largely unexpected dramatic failure?, (5) What are the policy implications that could minimize the likelihood of future foreclosure fallouts? By examining these systemic and behavioral factors, this paper identifies fundamental causes of the recent historical foreclosures through 
illustrations of how an assumed highly sophisticated but defective financial structure failed the mortgage lending and the financial system. The significance of the paper lies in the applications of behavioral measures to the dynamics of the capital market system and its explanatory value with critical insights as contributions to modern finance and economic theories. If the behavioral factors in the study were taken into account in regulations and policies, a global recession that left millions unemployed and homeless could have been avoided and the standard of living of millions would not have deteriorated due to vast capital losses. Specifically, the explicit impact of the behavioral causes in the study of mortgage foreclosures in the U.S. is shown in measurements such as mortgage foreclosure rates, home mortgage debt to disposable personal income ratios, and decreases in savings for the majority of the population in the U.S., which will have longterm implications for the growth prospect of the nation. A series of decisions, actions, and inactions that created a network of complex and fragile economy illustrated in the following sections show how policymakers and regulators can prevent further harms to the broader society for more sustainable economic development by taking the human behavioral factors into consideration.

\section{Bank Failure in Managing Mortgage Risks}

Lender Overconfidence, Anchoring, and Reference Dependence with Short-Term Data of Limited Relevance: While prior researchers have commonly discussed the historic changes in the mortgage lending system, the 'anchoring' behavior, which leans toward the first information received about a phenomenon, has generally not been considered (Barth et al., 2009). Anchoring is considered a psychological bias. It is the cause of under-reaction or overconfidence to potential events as the mind focuses either only on a simplified reference point, e.g., one numerical value, or past market data in projecting future events, which to a small and large extent could be different from previous ones. In the subprime lending case, the launch was largely based on assumptions or references of benign outcomes derived from and thus anchored on relatively shortterm past data of four to five years (The Financial Crisis Inquiry Commission, 2011) showing a downward trend in foreclosure rates (Fig. 2) and upward movement in home values.

Fig. 2: Foreclosure Inventory and Initiation Rates in the United States: 1960-2005

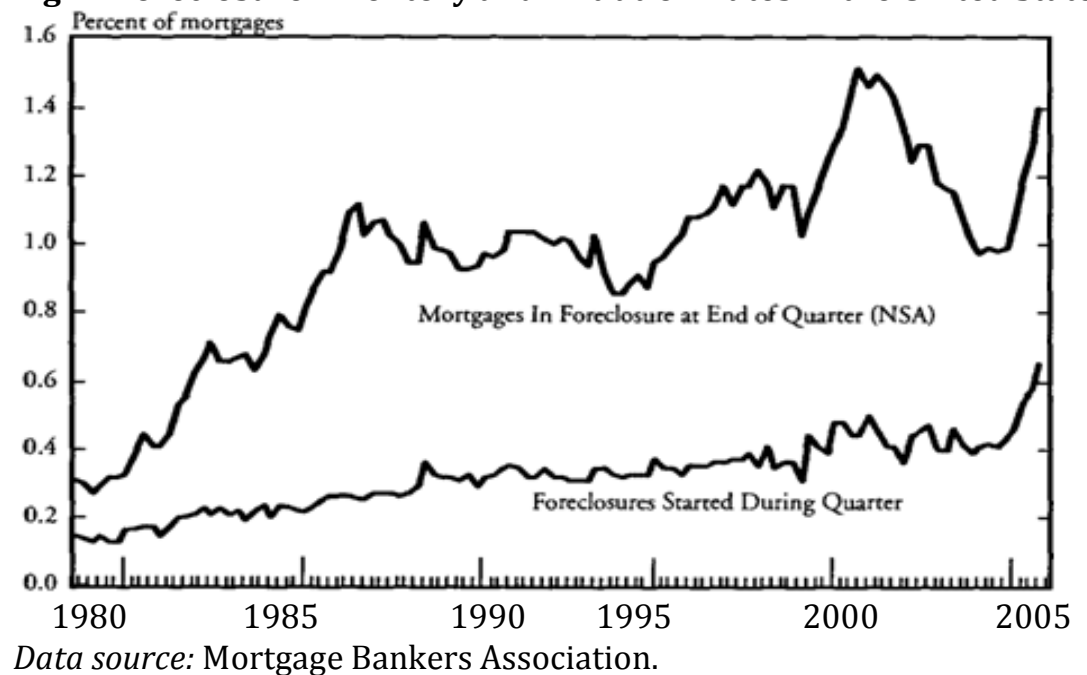

The decline in non-seasonal-adjusted foreclosure rate as a percentage of total mortgages outstanding between 2001 and 2005 was misleading due to increase in the overall mortgage loans in the period. Foreclosures took off after this period when outstanding mortgage debt exceeded disposable personal income at the aggregate level for all borrowers (Fig. 4). Also consider that traditional statistical measures concerning loan default probabilities are not always reliable measures because there may be lags behind foreclosure occurrences. Thus, it is the economic condition in development, such as interest rate changes, decreases in real estate prices, and increases in unemployment, that had a significant impact on foreclosures. Thus, the issue of overconfidence or anchoring was originated in the method of risk practice in a reductionist 
system ${ }^{1}$ among most banks where loan extension, $L_{e}$, is based on historical performance data, upon availability, of the prospect borrower, $P_{h}$, so

$$
L_{e}=f\left(p_{h t-1, \ldots t-n}\right)
$$

In reality, however, loan performance extended at time $t, L_{p, t}$, depends also on specific economic conditions, $E_{c}$, the nature of the product design based on the utilities of all market participants, $\delta$, which may vary over time such as changes in interest rate, as well as any unknowable factors, $\varepsilon$, that are derivative factors generated from correlations of other variables such that

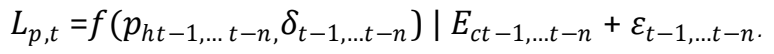

People were unaware of their lack of knowledge in the varying factors, $\delta, E_{c}$, and $\varepsilon$, which contributed to overconfidence leading to under-reaction or estimation. Similarly, loan performance at extension looking forward, $L_{p, e}$ depends on these unknown factors in the future with reflexive relationships among them given the financial innovation, $\delta$, and economic conditions, $E_{c}$, at the time:

$$
L_{p, e}=f\left(p_{t+1, \ldots t+n}, \delta_{t+1, \ldots t+n}\right) \mid E_{c t+1, \ldots t+n}+\varepsilon_{t+1, \ldots t+n} .
$$

In addition, in the recent foreclosure scenario, it was these unknowable future factors and the ramifications of the design of mortgage-backed-securities that triggered a bank run and subsequently a severe economic downturn leading to a historically high foreclosure rate that extended well beyond the subprime population. In the process of loan origination, lending decisions made by credit underwriters were largely based on quantitative models and measurements of the prospective borrower based on the borrower's historic and most current financial performance. This method of risk assessment, while is the best that most lenders are capable of managing, is partial and restrictive. The inherent risks in the subprime population, such as susceptibility to high unemployment and lenient credit extension policies using the existing home as collateral (Gerardi and Willen, 2008), were not incorporated into these models and analyses. Subprime mortgage borrowers are more sensitive to macroeconomic fluctuations than others in terms of solvency given constraints on financial resources. In other words, the performance of the subprime markets in terms of borrower capability in making mortgage payment is exaggerated to the positive during economic expansions and is likely to deteriorate when recession occurs. Motivations for increasing subprime lending were based on such false impressions: data with foreclosure rates moving downward at the end of each quarter between 2001 and 2004 in the United States (Fig. 2). Nevertheless, foreclosure is almost a certainty for this group of borrowers when the economy takes a downturn considering the overall financial challenges of the low-prime group including negative net savings rate and other liquidity constraints (Fig. 8). The selected short-term data, though unreliable given changing macroeconomic conditions, provided pretext for low default risk projections and the confidence to launch massive subprime and Alt-A MBS mortgage lending. In addition, the rating agencies based decisions on short-term historical performance data (anchoring), which reflected only a limited snapshot in a business cycle, along with biased scores generated by mortgage lenders in the process of modeling structured products such as collateralized debt obligation (CDO) ratings (The Financial Inquiry Commission, 2011). With government's encouragement for taking on highly leveraged home loans to foster broader homeownership, the launch of subprime lending resulted from overconfidence neglected underlying risks. Almost all parties involving mortgage lending exhibited overconfidence and 'anchored' on data that did not provide a full picture of borrowers' financial ability and the probability of repayment from a long-term perspective. This 'reference-dependent' behavior permitted acceptance and even solicitation of mortgages that were not stable at the early stages of lending practice.

Projection Failure in a Reductionist System with Bounded Rationality and Historical Data: In addition to the shortfalls of overconfidence, anchoring, and reference-dependent behavior by lenders and real estate appraisers ignoring a particular phase in a property market cycle, there are causal or correlation issues among variables and relying on findings studied in a reductionist system. Relevant variables may have been

\footnotetext{
${ }^{1}$ Reductionism explains a complex system as the sum of its parts and emphasizes causal factors. Unlike those in the physical or natural sciences, activities in finance and economics are reflexive and correlated given human input. A holistic perspective, which considers a complex system as non-linear, correlated, and inherently irreducible is more accurate and appropriate in analyzing and understanding market behavior.
} 
excluded given lack of longer historical data. There were issues of whether variables used have a causal-effect or correlation among them in deeming the validity of their relations. According to recent research, the past debt to income (DTI) ratio, a critical indicator used in loan underwriting, does not appear to be a strong predictor of default (Foote et al., 2009). The finding coincides with the fact that borrower default decisions depend on mortgage payment relative to the borrower's income in the present or future but not in the past. Nonetheless, data on subprime foreclosures as a group supported the finding from a different perspective: there was a 77.5 percent foreclosure increase in 2003 when hybrid interest rates expired (Barth et al, 2009). Conversely, short-term data on declining foreclosures as a percentage of all mortgages between 2001 and 2004 (Fig. 2) were due to increases in real estate prices and the overall mortgage originations, a denominator of the ratio. The collapse of subprime lending is the empirical proof of bounded rationality in a reductionist system. Although one study shows that borrower credit scores are robust predictors of delinquency, default, and prepayment, and LTV at origination is positively correlated with delinquency, the study results were based on a particular set of economic conditions along with specific technology and financial innovations in place at the time (Danis and Pennington-Cross, 2008). Conclusions based on correlations among variables of borrowers' past financial performance in predicting probability of future default can be misleading given the idiosyncratic nature of variables in a particular period. Similarly, while some structured products seemed to work well in a boom cycle in the U.S. economy, they could not withstand the test as long-term investments or debt instruments given changes in the external environment. A study by Coval et al (2009) shows that structured products such as MBS are unable to endure in economic downturns. As discussed earlier, lending decisions made by financial institutions were based on past data for prospective borrowers with a focus on financial performance and restrictions in a reductionist system. However, projections of future macroeconomic conditions in a complex global environment may not be factored in the lending practice, technology nor human skills were advanced enough to make such forecasts with sufficient accuracy. In addition to the volatilities CDOs brought to the market, which exacerbated the expansions and intensified the contraction in the economy, transparency was lost given complexity in identifying early signs of hazardous foreclosure behavior in the subprime population during economic expansion as shown in Fig. 3.

\section{A Fragile and Conflicting System with Mortgage-Backed-Securities Subprime Lending with Riskier Borrowers and Non-Committal Creditors}

Subprime mortgage lending was influenced by lending in the unsecured credit and micro-lending markets (e.g., mortgages extended under the Community Reinvestment Act). However, unlike other types of subprime lending, the sizes of loans in subprime mortgages were much larger and the sources of credit under residential MBSs were fundamentally different from those that were usually guaranteed by either the banks or the government. During the height of the subprime mortgage lending, the vast majority (68 percent) of the funding came from securitization (Barth et al, 2009). Unlike other types of credit extensions where banks or governmental agencies were the suppliers, residential MBSs lead to serious liquidity problem when fears of defaults develop among investors leading to liquidity crisis or bank run.

Fig. 3: Foreclosures Initiated on Conventional Subprime Mortgages.

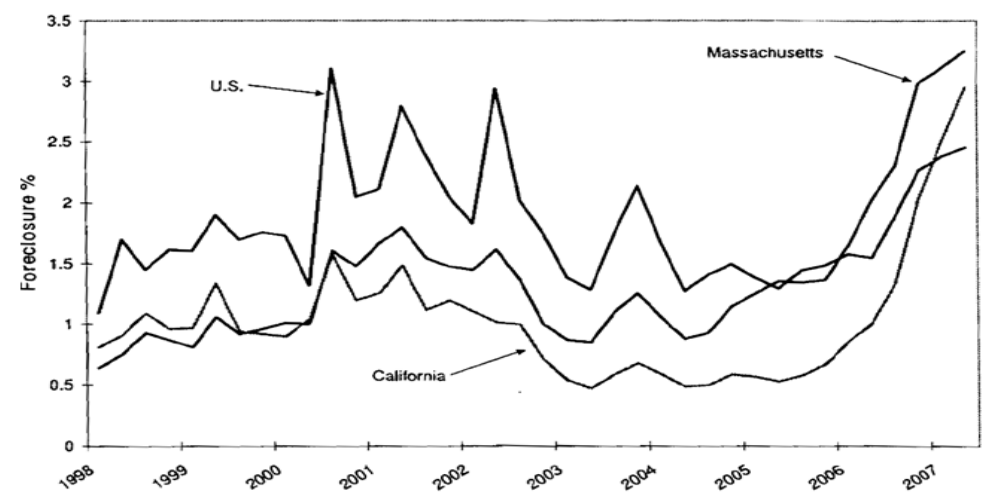

Data source: Gerardi, K. et al, 2008. 
The national average foreclosure rates of the subprime group in the U.S. had been volatile since 2000. Early signs of significant and persistent nationwide increase in foreclosures since 2005 and in the states of Massachusetts and California in particular (both of which held large portfolios of subprime mortgages), did not serve enough warnings to continued credit expansion in the names of financial innovation. Subprime Outcomes: Risky Mortgages, Homeownership Experiences, and Foreclosures. Federal Reserve Bank of Boston working papers. Moreover, similar to those of unsecured credit lending, terms of baseline repayment in mortgage loans appear to be economical but are inefficiently front-loaded with origination fees, points to brokers, down payments, and other settlement costs. In addition, any delays may result in large penalties. Consequently, borrowers often over-borrow, pay the penalties, and back load repayment hence suffering large utility losses (Heidhues and Kőszegi, 2010). As subprime borrowers are already pressed between higher interest rates and constrained liquid assets, the loss of utility due to various fees further contributes to higher probability of default in this group. Thus, as new borrowers are eager to take on mortgage debt in attaining the "American Dream" of homeownership, they inadvertently increase financial risks caused by lost wage or other financial shocks such as interest rate changes. Moreover, according to a study on lower-income homeownership, products such as hybrid adjustable rate, interest-only, and negative amortizing, loans targeting the subprime markets create instrument risk (Bostic and Lee, 2008). Since these products require extensive financial knowledge to be used effectively and the lower-middle income households have consistently been shown to have lower levels of financial literacy (Maki, 1996), subprime lending introduces new risks to mortgage foreclosures. Further, efforts to generate funding with demands of high returns from investors to be loaned to risky home borrowers without the means and resources for mortgage repayment created a situation where objectives for funding and borrowing were essentially mutually exclusive.

Illusion of Control: Mental Framing ${ }^{2}$ from Tension Building to Implosion: Many inherent tensions and conflicts of interest were generated in the process of implementing innovative MBS products that evolved into an extremely fragile system. As the Financial Crisis Inquiry Commission reports (2011), "The three credit ratings agencies were key enablers of the financial meltdown. The mortgage-related securities at the heart of the crisis could have been marketed and sold without their seal of approval." Rating agencies were pressured to give high ratings because of competition while seeking high service fees. Intermediaries, or investment banks, were eager to expand credits to secure commissions and management fees for high revenues by taking higher risks. Loan originators earned revenues by selling mortgages irrespective of long-term loan quality requirements and financial liabilities as borrower risks were shifted off the financial institution balance sheets. As investors demanded higher returns for taking on the risk for residential MBS, mortgage borrowers were willing to pay for the entire home price for which they were qualified by banks. These homeowners saw an opportunity. They effectively "framed" the background of the context choices promoted by lenders as achieving the "American Dream", in which they could move from rental to ownership or from smaller to "bigger and better." The entire home buying process is an emotional experience for borrowers, relies heavily on buyer trust of real estate and mortgage brokers (Woodward and Hall, 2010) and on numerous heuristics such as framing and illusion of control. ${ }^{3}$ According to Shefrin (2008), in selecting the preferred combination of choices, it involves computing the summation value of

$$
\sum_{k} n=-m^{v} k^{u}\left(x_{k}\right) \text {, }
$$

Where it represents all possible outcomes and people will choose the combination with the highest perceived value. Given the ready access to mortgages, often with little to no income verification, low interest rates as an initial offer for adjustable rate mortgages ("teaser" rates), and the high emotional value found in immediate homeownership, the perceived high value of taking a mortgage under framing among subprime borrowers was inevitable. While insatiability was a factor for some borrowers taking on mortgage debt, time

\footnotetext{
${ }^{2}$ Mental framing refers to the environmental influences of a social phenomenon constructed by specific organizations. In the mortgage lending case, it is an inevitable process of selective influence over the individual's perception of value and the meanings attributed to promotions from the banks and the government.

${ }^{3}$ Illusion of control is the tendency for human beings to believe they can control, or at least influence, outcomes that they demonstrably have no influence over. It has been demonstrated in a succession of different experiments, and is thought to influence gambling behavior and belief in the paranormal (Vyse, 1997).
} 
discounting 4 and sequential decision-making were key factors during the run-up to the foreclosure crisis. For all parties involved in the mortgage debacle, bounded rationality including cognitive biases, such as mental framing and hyperbolical discounting, contribute to seemingly logical and rational short-term decision that in reality became erroneous. While real estate is considered real asset and all market participants expect to benefit from the innovative growth in MBS, property market tied to other financial derivatives can be misleading given the absence of resources for credit demand and incentive variations in credit supply discussed above. Meanwhile, the intensity of conflict of interests among market participants triggers a systemic implosion. To illustrate this point, home mortgage debt as a percentage of personal disposable income reached nearly 140 percent in 2007, as shown in Fig. 4, while shares of disposable personal income among quintile groups remained similar across time, as shown in Fig. 5.

Fig. 4: Home Mortgage Debt to Disposable Personal Income Ratio in the US.

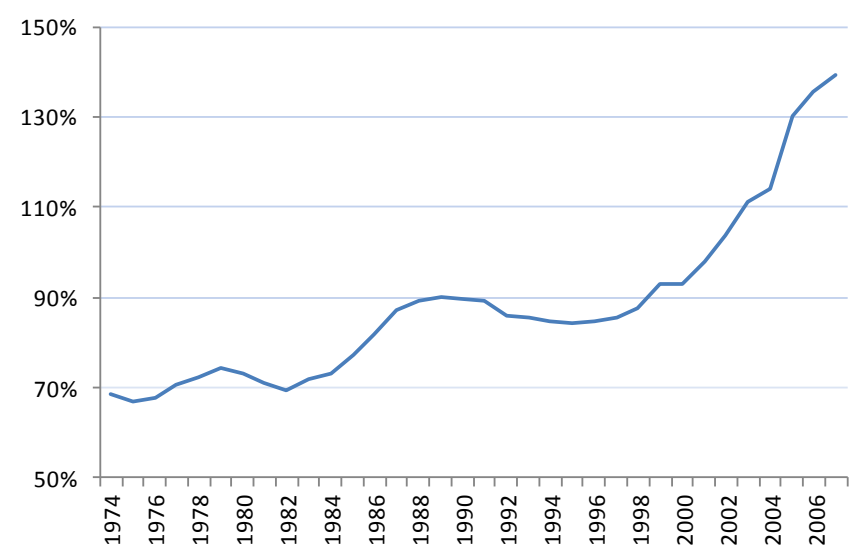

Data sources: U.S. Census Bureau and the Federal Reserve Bank.

The ratio exceeded $100 \%$ since 2002 , an indication of strenuous personal financial conditions as net savings of the majority of the U.S. population deteriorated (Fig. 8). Yet mortgage lending continued to expand until 2008. On the lending side, bank and real estate related equities that reflected the performance of these entities rose noticeably before the market crash, as demonstrated in Fig. 6.

Fig. 5: Shares of Disposable Income in Quintile Groups from 1979-2006.

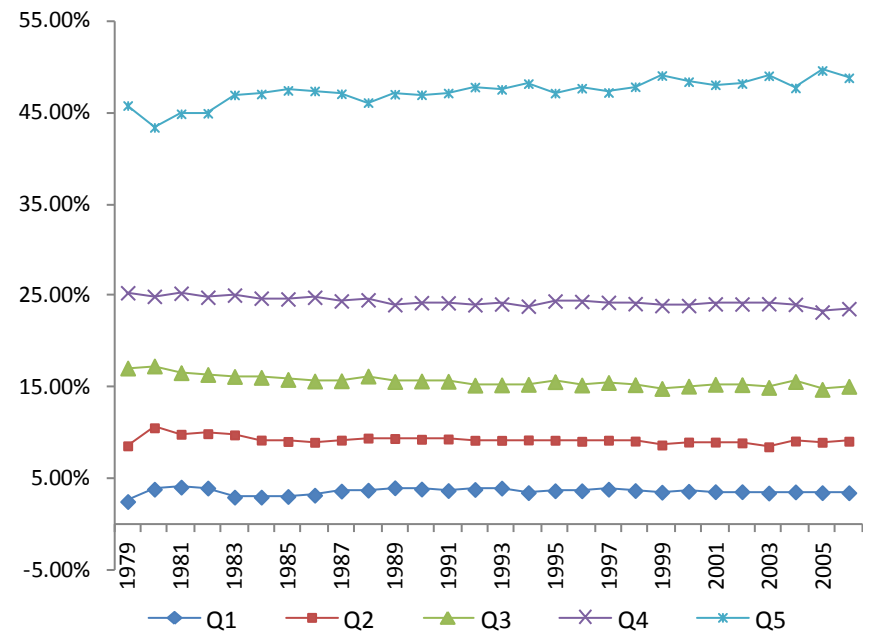

Data source: U.S. Census Bureau

\footnotetext{
${ }^{4}$ Hyperbolical or time discounting occurs when borrowers prefer near term benefits or value short-term gains higher than those for long-runs.
} 
As the U.S. economy sought for growth in mortgage lending in the subprime group and beyond, financial implosion occurred when shares of disposable income among these populations maintained stagnant. Note: The quintile groups are divided by income ranges of the U.S. population according to standards of the U.S. Census Bureau.

Fig. 6: Equity Values of Bank of America (BoA) and Real Estate: 8/1993-6/2010.

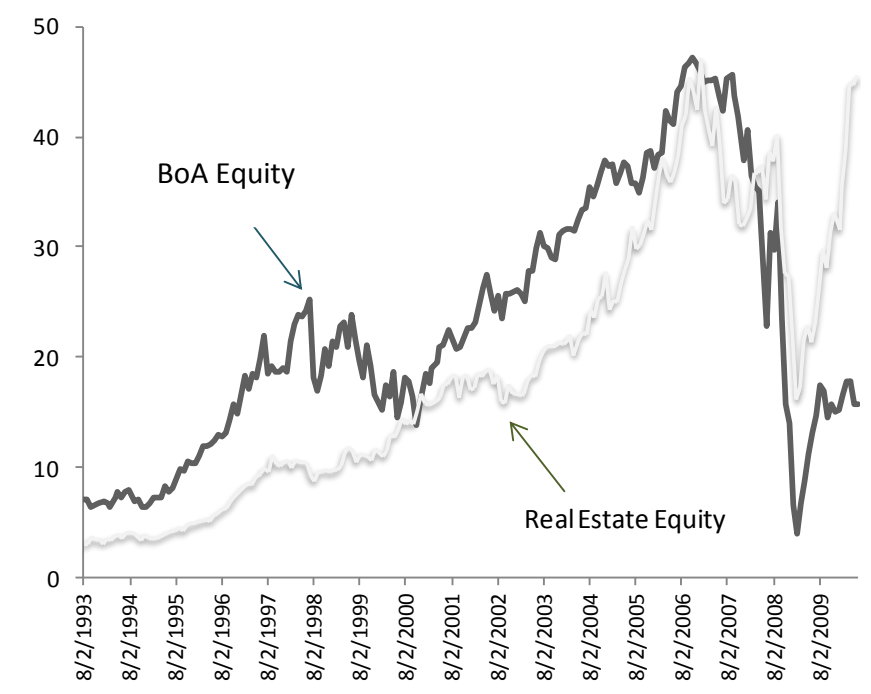

Data source: Yahoo! Finance

Stock prices reflected the performance of the company and the market sector as mortgage lending soared. The graph also illustrates how two distinctive sectors are closely correlated in an economy across time before and after the 2008 crisis.

\section{The Symptom of Myopia: Incompatibility in Investment and Profit Making Objectives and the Two- Speed Sector System}

Market incompatibilities existed between borrowers seeking long-term investments in housing versus banks or investors seeking short-term profits. While industries with high liquidity such as the financial sector reaped high fees and short-term benefits, many who purchased real estate properties needed years of income to endure risks through decades of economic cycles to avoid mishaps. As most financial intermediaries reaped seasonal or short-term gains during boom time, losses occurred during recessions were shifted to other market participants and the society even beyond the historic foreclosure rates. During the typical 30year residential mortgage payment, the survivability of borrowers was challenged in the first few years, especially when teaser rates expire (Fig. 7). Financial crisis is almost a certainty when an economic contraction coincides with these vulnerable periods considering the volume of the mortgage debt outstanding in the economy. The design of the residential MBS, connecting the liquid financial sector with the low liquidity real estate market, creates serious disequilibrium or disruptions in the liquidity flow between investors and borrowers given the varied speeds at which these sectors operate. While the abundance of cash from investors demanding higher returns for taking the risks of lending to liquidity-constrained groups made the initial funds available for mortgage loans, defaults had to occur considering the affordability issues for cashstrapped borrowers. Fig. 8 shows that starting from the mid-1980s and the late 1990s, net savings of the middle and upper-middle income groups in the U.S. moved into negative territories, joining the low- and lower-middle-income groups. This change coincided with the continuous increase in home mortgage debt, particularly in the same periods when mortgage debt exceeded disposable income (Fig. 4). These data indicate an imminent conflict of interests among players in the mortgage market given uneven distribution or lack of financial resources. Bank runs and liquidity crises were inevitable. 
Fig. 7: Baseline Default Hazards: Prime and Subprime Loans.

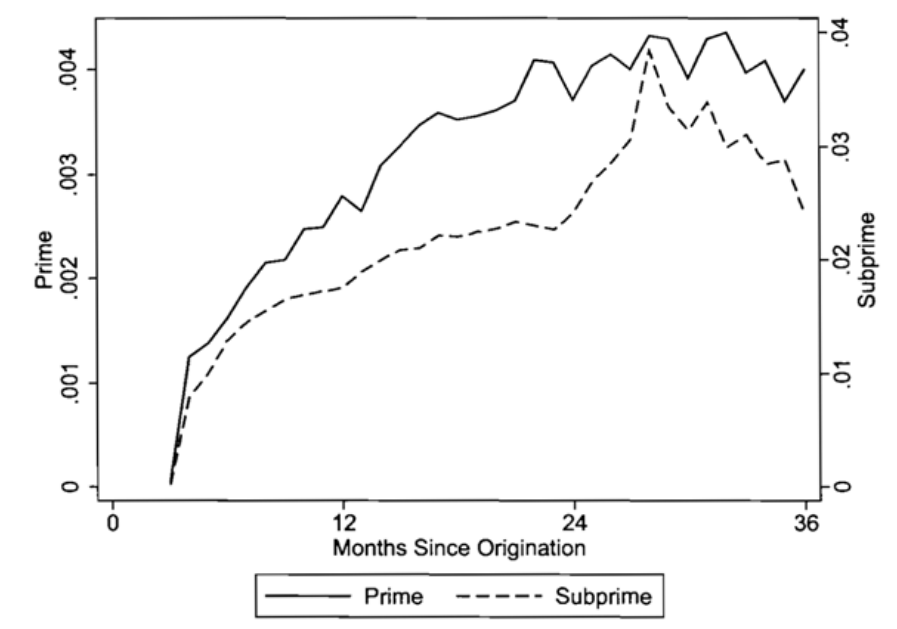

Data source: Foote, C. et al, 2009. Reducing Foreclosures. Federal Reserve Bank of Boston working papers.

Defaults among the subprime and the prime mortgage borrowers tend to occur when teaser rates expire around the second to the $3^{\text {rd }}$ year after loan origination. As the mortgage debt to disposable income ratio leaped from $114 \%$ to $130 \%$ between 2004 and 2005, a historically largest increase in the ratio (Fig. 4), the default window showing above coincided with the economic contraction in 2008.

The Creation of a Defective System with Complex Products: Each wave of mortgage foreclosures in the past had its economic and geographic distinctions as well as commonalities and the most recent wave of foreclosures was no exception. As one would expect lenders had learned from the past thus are able to avoid another major real estate crash, we encountered a yet even higher and more persistent foreclosure storm in the current crisis cycle. In the following section, we apply additional behavioral characteristics to explain mortgage lending patterns and factors that brought the U.S. real estate market to a record level of foreclosures.

Fig. 8: Savings in Quintile Groups (\$Bln) 1979-2006.

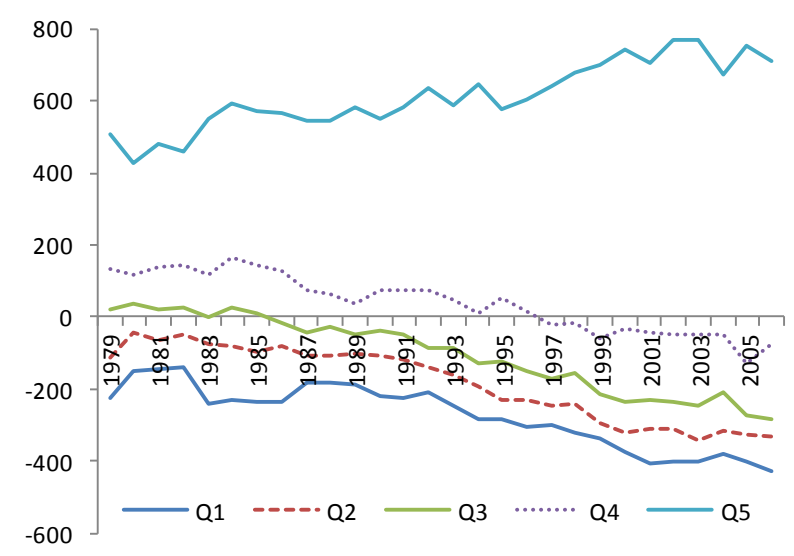

Data source: Bureau of Labor Statistics, U.S. Census Bureau, Federal Reserve Bank

Savings declined for the lower 4 quintiles groups as mortgage debt overtook disposable personal income (Fig. 4). The graph illustrates that the majority of the U.S. population were under financial stress. Note: Net savings across five income groups were estimated using variables including disposable personal income, consumption, revolving credit, interest payment on credit, and bank charge-offs in real terms. 
Complexity Found in Vacuity with Endogeneity Expansion: As nature created people with heterogeneous behavioral and cognitive attributes and abilities (Eagleman, 2011), the mortgage financing system created challenges for banks which generate simplified or biased financial models primarily based upon and expect homogenous or limited heterogeneous thought and behavioral patterns in humans (Derman, 2011). In addition to forming a fragile mortgage-lending network given various conflicts of interests discussed above, the complex MBS design existed essentially in the abstract and at a theoretical level that ignored and worked in contradiction with the most fundamental human behavior of the majority of borrowers and investors. In other words, the complex MBS products designed on paper have few real connections with the complexity of real market actions and reactions. In line with the findings on macroeconomic contingencies, the performance of a complex financial product such as MBS depends on an expanded variety of endogeneity given the intricacies of how the products deliver. While designed mostly for short-term profits, neglecting side effects and consequences of these products, complex financial innovations prevailed in financial systems, which barely had the defense mechanisms for the level of risks that these products engendered. In sum, residential MBS proved to be ineffective for the majority of the borrowers as a long-term investment tool and too challenging for lenders and investors to predict and manage the multi-level risks due to information asymmetry, imperfect regulations, limited human cognitions and biases, and other economic externalities. The level of product complexity in finance had led to increasing unknowns and uncertainties in an economy. In addition, it is either too costly or impossible to project the outcomes of human inputs ex ante at a meaningful level under multiple scenarios that occur simultaneously.

Ambiguity Aversion ${ }^{5}$ or Default Contagion: Macroeconomic Externalities and Assumptions of Individual versus Collective Behavior: One of the important assumptions in the designs of the structured products or CDOs was that risk is reduced due to its diffusion among a greater number of creditors. While the credit risk was reduced for individual banks as they shifted most of the risks to investors, the aggregate risk was much larger in the system as a whole with CDOs. Nonetheless, models for CDO designs further assumed that although more investors were taking risks, these risks were not correlated because of the tranches of risk levels. Hence, a systemic collapse was assumed impossible. However, empirical evidence shows that even the safest tranche or AAA rated CDO investors withdrew during the height of the recession (Coval et al, 2009). While bankers made biased assumptions in a reductionist system with beliefs in individualistic or uncorrelated behavior that led to misjudgment of the occurrence of systemic risk, behaviorists recognized long ago that people act collectively under fear or panic (Skinner, 1976); a scenario in a bank run. While herding behavior in the market is ubiquitous due to fear, ambiguity aversion among investors leading to the initial liquidity crisis can be confirmed by the Ellsberg Paradox, which concludes that people are averse to ambiguity and place greater value on known factors than unknown ones. So

Where

$$
K_{v}>U_{v} \text {. }
$$

$K_{v}=$ perceived value of known factors

$U_{v}=$ perceived value of unknown factors

Coval, et al (2009) found that small errors that were not significant in a single name market were substantially magnified under the CDO structure and could be further magnified when CDOs were created from tranches of other CDOs in mortgage-backed-securities. As investors realize the predisposition and unreliability of ratings leading to distrust, the complexity, uncertainty, and unknowable factors associated with residential MBS products dominate in the decision to sell-off. This collective action, or herding behavior, as a result of fear was in sharp contrast to the original assumptions in the creation of the MBS instrument; risks identified by various tiers or tranches are isolated and expected to be uncorrelated. The correlated risks among various tranches that triggered investor fear and a collective sell-off can be explained further by the inherent risks in the subprime populations and the market risks infected the prime borrowers. According to Gerardi et al. (2008), subprime mortgages are five to six times more likely to default than those in the prime population are and are likely to be the first to default when an economic downturn occurs. In addition, as interest rate structures, such as adjustable rate mortgages with low "teaser" rates, lured the higher-risk groups into taking up mortgages, many borrowers in the prime population who qualified for traditional loans also were drawn to these 'attractive products.' As circumstances of mortgage payments change causing home

\footnotetext{
${ }^{5}$ Ambiguity aversion occurs when investors prefer known risks over unknown risks.
} 
prices to decline, defaults of the combined subprime and prime populations add further stress to the overall economy leading to crisis. This outcome of default contagion due to correlated risks is supported by other studies. Coval et al (2009) found that performance of the securities created by tranches of large asset pools were strongly affected by the performance of the economy as a whole and the effect of the exposure to which was not captured in the ratings. It was the worsened economic conditions and contraction along with a high unemployment rate and real estate price declines that led to defaults and foreclosures spreading beyond the subprime borrowers.

Thus, contrary to what most financial risk models anticipate, the actual home loan defaults can be significantly more than what is projected because of real estate market conditions and other externalities and incentives to default. For subprime and prime borrowers, the ability to maintain monthly mortgage payments depends primarily on macroeconomic environment, e.g., housing price levels and employment status. A study by Gerardi (2008) showed that during 1994 to 2007, the success factors for subprime population to maintain homeownership were the increasing housing prices and lowered lending standards when homeowners were able to borrow against their homes. The finding confirms that changing economic conditions and externalities can be deterministic factors in borrower solvency, and that these were, in most cases, beyond lenders' projection capacity. Another factor that contributed to the collective foreclosure behavior was 'ruthless default' due to negative equity permitted under the U.S. legal system. The liquidity crisis led to tightened lending standard from the banks while prime and subprime mortgage borrowers continued to default given their high level of indebtedness with low savings, high unemployment rate, and other negative macroeconomic conditions. Subsequently, credit and mortgage loan contraction caused real estate prices to plummet leading to negative home equity. One study suggests that 90 percent of the variation in foreclosure can be explained by the presence of negative equity (Foster and Order, 1984). Coinciding with falling real estate prices, the evaporation of residential MBS caused by liquidity crisis was in line with findings that securities of younger and high volatility are likely to be disproportionately sensitive to broad waves of investor sentiments such as sell-off (Baker and Wurgler, 2007). Therefore, the very investors who had helped to fuel the availability of mortgage capital triggered a tightening of credit as they moved to sell-off their investments. This instance further demonstrates that MBS of considerable size contributes to the instability of the lending and financial system.

Product Design with Self-Serving Bias in Dissonance with Progressions of Behavioral Fundamentals: In the past decade, fundamental mechanisms and sequences in human behavior in the market ambiance have worked gravely at odds with the networks of the highly complex financial products. These innovations, which were designed under the influence of self-serving biases ${ }^{6}$ for short-term gain, ultimately contributed to the malfunctioning of the mortgage market and the massive home foreclosures. These market mechanisms and human behavior, or lack thereof, include: covert costs incurred due to uncertainties given the level of risk taken (e.g., bank runs, defaults due to changes in loan terms or borrower income deficiency), information asymmetry due to limitations of data (e.g., no income verification), loss aversion ${ }^{7}$ as a result of fear due to uncertainty or contingency caused by product complexity (Skinner, 1976), and other market imperfections. When banks launched subprime mortgage lending, there was risk seeking among all parties. However, market participants turned risk averse as losses loomed larger than gains in magnitude (Shefrin, 2010) or

Where

$$
L_{p, n}>G_{p, n}
$$

$L_{p, n}=$ perception of loss at level $\mathbf{n}$

$G_{p, n}=$ perception of gain at level $\mathrm{n}$.

Though these less observable behavioral factors are not directly quantifiable in financial models, they paved the way for catastrophe with almost certainty from behavioral standpoint; loss aversion occurred during

\footnotetext{
${ }^{6}$ Self-serving biases lead people to see data in the way they want to see or to select or distort facts to suit their preferences and business needs, though maybe unintentional.

${ }^{7}$ A concept of prospect theory, which denotes that the utility of market participants depends on deviations from moving reference, points rather than absolute wealth. In the subprime mortgage lending case, market participants tend to avoid further losses from previous ones.
} 
bank run among investors and default choices among borrowers when home values fell below mortgage levels. Behaviorists have recognized through studies of bounded rationality (Simon, 1957) and prospect theory (Kahneman and Tversky, 1979) that humans rely upon heuristics to assess expected utility when faced with complex choices. Subsequently, the behavioral outcomes of the market makers that led to market failure reflected also the failure of the complex product designs in the lending process. In addition, when borrowers experience time discounting with varied discount rates across the decision horizon (Diamond and Vartianinen, 2007), mortgages may not be regarded as obligations by the borrowers in the way lenders expect; rather as a means to the immediate goal of homeownership or improved homeownership. Moreover, mortgage borrowers, low-income groups in particular, experience the behavioral factor of sequential decision-making involving trust and representativeness ${ }^{8}$ in borrowing decisions as well as in default. The importance of trust in financial relationships, particularly for the less affluent has been widely reported (Carr and Schutz, 2001). In the case of the low-income mortgage borrowers before the crisis, trust was built on representativeness to the extent that borrowers established probabilities of outcomes based on how well the example represents the class (Camerer and Loewenstein, 2003); though they may have misjudged probabilities based on their knowledge. In the foreclosure crisis, it was the misjudgment of the lenders, insurers, raters, and real estate agents as actors in the names of the best interests of borrowers that contributed to borrower over-leverage and under-preparation for economic adversity. Fig. 9 illustrates and summarizes how a series of human behavior in sequence had led to the current high foreclosure rate in the system.

\section{Fig. 9: Systemic and Behavioral Sequence in the Mortgage Lending Market.}

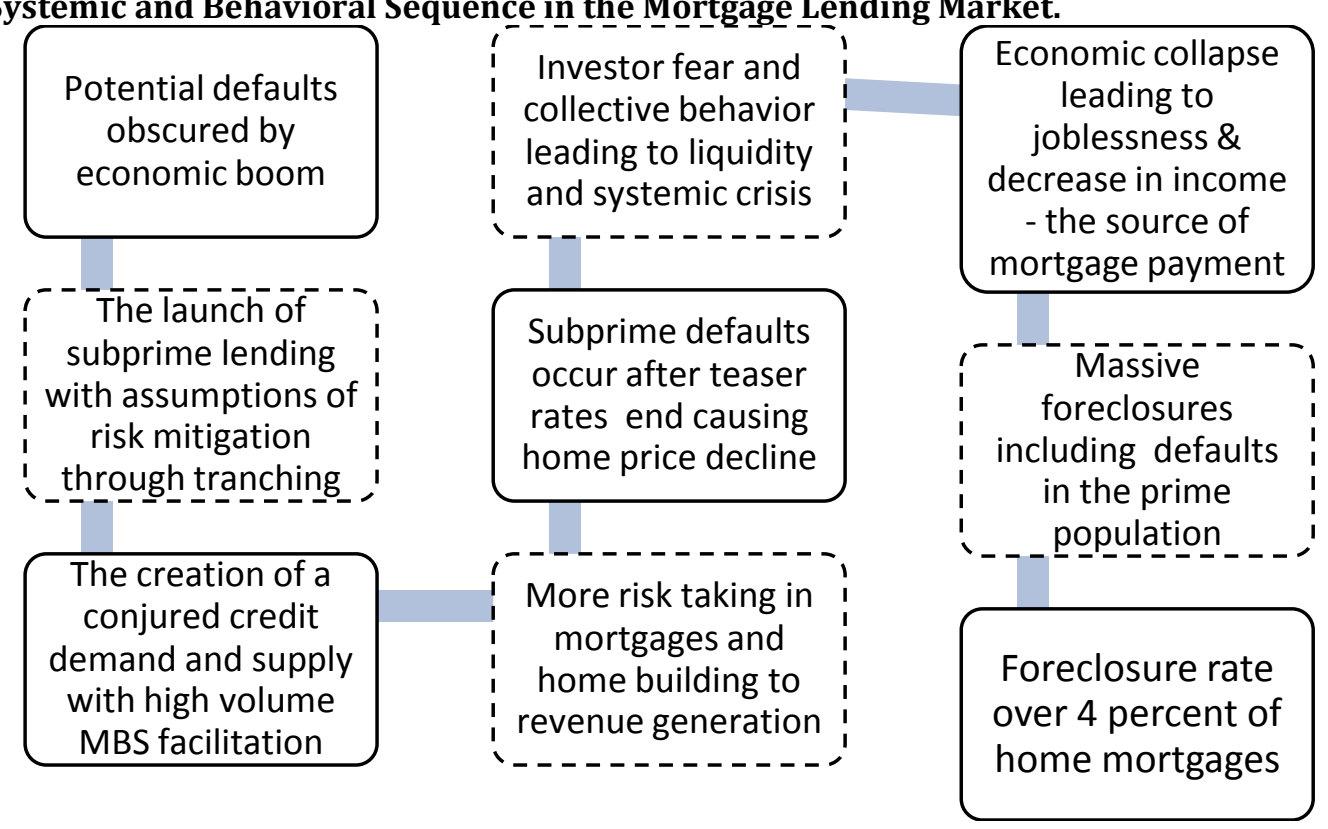

Summary of the development of the home mortgage lending in the U.S. leading to the 2008 financial crisis and the current state of foreclosures

\section{Conclusion}

The foreclosure crisis in the United States resulted from the confluence of numerous financial and behavioral factors that led to the 2008 economic downturn. In the past, analysts have identified factors such as weak borrower credit scores, high loan-to-value ratios, declining real estate values, adjustable rate mortgages, and general over-extension of credit as causes of home mortgage foreclosures. In this paper, however, we identify

\footnotetext{
${ }^{8}$ Representativeness refers to scenarios where individuals who overweigh information or develop a belief system based on values with salient characteristics. In the subprime mortgage lending case, low-incomers took out mortgages as many see their peers did so under the encouragement of all involving parties in the lending process.
} 
human behaviors as influential causes in home foreclosures given designs of the residential mortgage-backsecurities and lending procedures in the system. In other words, the behavioral mechanisms discussed in the study were manifestations of or reflections to seemingly justifiable incentives to mortgage expansion given product design, which in reality not only creates more uncertainties but also exacerbates product errors due to complexity and human characteristics that trigger the mortgage fallout. Specifically, we have shown bounded human rationality in quantitative measures, the problem of using historical and short-term data in predicting future events while overlooking human behavior such as overconfidence, mental framing, and ambiguity aversion. We have also illustrated symptoms of myopia, time discounting, and self-serving biases that dominated reasoning when the liquidity issue and limitations of financial resources among low-income mortgage borrowers were evident. Along with defective mortgage product designs that exacerbated information asymmetry and resource misallocation, these human behaviors, absent from the protective mechanisms of regulations, created a fragile lending system in an interconnected economy that led to a severe financial crisis with high level of home foreclosures. There is a fine line to tread in analyzing the product and policy implications of these factors. While a flawed financial product such as residential MBS can be destructive, the corresponding advancement in technology and regulatory systems need to be present as complementary and control mechanisms for the risks taken. Overconfidence paired with a reductionist system leading to market failure provided empirical evidence that internal-regulatory or risk control technologies in lending institutions, as well as external-regulatory systems such as the Securities and Exchange Commission or the central banks, are seriously lagging in monitoring and controlling risks in behavioral terms in the market. Additionally, long-term improvements in financial literacy among prospective borrowers need to be attained at all levels of the society. Lastly, income disparities beyond natural levels need to be reduced to limit the potential for future mortgage market failures of this magnitude when growth is the target in a nation's economic development. As policymakers and program directors revisit their efforts and evaluate new ones, thoughtful consideration should be given to whether there might be unintended consequences that offset the positive intended consequences in the development of an economy. One aspect that warrants consideration is to learn from the history of foreclosures, recognizing that no single factor accounted for the entirety of a calamity. As financial products are designed, care should be taken to avoid anchoring decisions on too short-term data. Most importantly, behavioral factors need to be weighed into product designs, lending processes, and performance expectations.

\section{References}

Baker, M. \& Jeffrey, W. (2007). Investor Sentiment in the Stock Market. Journal of Economic Perspectives, 21(2), $129-52$.

Barth, J. R., Li, T., Lu, W., Phumiwasana, T. \& Yago, G. (2009). The Rise and Fall of the U.S. Mortgage and Credit Markets: A Comprehensive Analysis of the Market Meltdown, Hoboken, NJ: John Wiley \& Sons.

Ben-Shahar, D. (2008). Default, Credit Scoring, Loan-To-Value: A Theoretical Analysis of Competitive, NonCompetitive Mortgage Markets. Journal of Real Estate Research, 30(2), 161-90.

Bostic, R. W. \& Lee, K. O. (2008). Mortgages, Risk, Homeownership Among Low- and Moderate-Income Families. American Economic Review, 98(2), 310-14.

Camerer, C. F., Loewenstein, G. \& Rubin, M. (2003). Advances in Behavioral Economics, Princeton, NJ: Princeton University Press.

Carr, J. H. \& Schutz, J. (2001). Financial Services in Distressed Communities: Framing the Issue, Finding Solutions, Washington, DC: Fannie Mae Foundation.

Chang, B. Y. (2010). Investor Behavior and Economic Cycle. Advances in Behavioral Finance and Economics, $1(1), 1$ - 26.

Coval, J. J. \& Stafford, J. F. (2009). The Economics of Structured Finance. Journal of Economic Perspectives, 23(1), 3 -25.

Danis, M. A. \& Pennington-Cross, A. (2008). The Delinquency of Subprime Mortgages. Journal of Economics \& Business, 60(1/2), 67-90.

Derman, E. (2011). Models. Behaving. Badly. (1st ed), New York, NY: Free Press.

Diamond, P. \& Vartianinen, H. (2007). Behavioral Economics and Its Application, Prinston, NJ: Princeton University Press.

Eagleman, D. (2011). Incognito: The Secret Lives of the Brain, New York, NY: Vintage Books of Random House. 
Edmiston, K. D. \& Zalneraitis, R. (2007). Rising Foreclosures in the United States: A Perfect Storm. Economic Review, 92(4), 115-45.

Elul, R., Souleles, N. S., Chomsisengphet, S., Glennon, D. \& Hunt, R. (2010). What Triggers Mortgage Default? American Economic Review, 100(2), 490-94.

Foote, C. L., Gerardi, K., Goette, L. \& Willen, P. S. (2008). Subprime Facts: What (We Think) We Know about the Subprime Crisis and What We Don't. Research Review, (9), 6-11.

Foote, C. L., Gerardi, K. S., Goette, L. \& Willen, P. S. (2009). Reducing Foreclosures. Research Review, (11), 7-10.

Foster, C. \& Order, R. V. (1984). An Option-Based Model of Mortgage Default. Housing Finance Review, 3(4), $351-72$.

Gerardi, K. S. \& Willen, P. S. (2008). Subprime Mortgages, Foreclosures, and Urban Neighborhoods. Research Review, (10), 6-12.

Heidhues, P. \& Kőszegi, B. (2010). Exploiting Naïvete about Self-Control in the Credit Market. American Economic Review, 100(5), 2279-303.

Kahneman, D. \& Tversky, A. (1979). Prospect Theory: An Analysis of Decision under Risk. Econometrica, 47(2), 263-91.

Loewenstein, G., O'Donoghue, T. \& Rabin, M. (2003a). Projection Bias in Predicting Future Utility. Quarterly Journal of Economics, 118, 1209-48.

Loewenstein, G., Read, D. \& Baumeister, R. (2003b). Time and Decision: Economic and Psychological Perspectives on Intertemporal Choice, New York, NY: Russell Sage Foundation.

Maki, D. M. (1996). Portfolio Suffling and Tax Reform. National Tax Journal, 49(3), 317-29.

Mortgage Bankers Association. (2010). Delinquencies, Foreclosure Starts Fall in Latest MBA. Mortgage Bankers Association Press Release, Februry 19.

Shefrin, H. (2008). A Behavioral Approach to Asset Pricing, Massachusetts: Academic Press.

Simon, H. A. (1957). A Behavioral Model of Rational Choice. The Quarterly Journal of Economics, 2, 99-118.

Skinner, B. F. (1976). About Behaviorism, New York, NY: Vintage Books of Random House.

The Financial Crisis Inquiry Commission. (2011). The Financial Crisis Inquiry Report: Final Report of the National Commission on the Causes of the Financial and Economic Crisis in the United States, Tennessee: PublicAffairs.

Vyse, S. (1997). Believing in Magic: The Psychology of Superstition, Oxford, UK: Oxford University Press.

Woodward, S. E. \& Hall, R. E. (2010). Consumer Confusion in the Mortgage Market: Evidence of Less Than a Perfectly Transparent and Competitive Market. American Economic Review, 100(2), 511-15. 